\title{
Evaluation of Exotic Germplasm of Barley [Hordeum vulgare (L.)] for Stability Parameters
}

\author{
Om Vir Singh*, Kartar Singh and Neelam Shekhawat \\ National Bureau of Plant Genetic Resources, Regional Station, Jodhpur \\ *Corresponding author
}

Keywords

Barley, Hot arid climate, Accession $\mathrm{x}$ environment interaction,

Crossover and noncrossover interactions, Regression analysis

Article Info

Accepted:

15 June 2018

Available Online:

10 July 2018

\section{A B S T R A C T}

Forty accessions of barley (Hordeum vulgare (L.)) were evaluated during five Rabi seasons i.e. year 2012-13 to year 2016-17 for eight quantitative traits and data were subjected to regression analysis and also the analysis to detect the presence of crossover and non-crossover interactions. Ten accessions EC 667471, EC 667384, EC 667441, EC 667500, EC 667613, EC 667550, EC 667603, EC 667567, EC 667369, and EC 667533 were identified to be promising using regression analysis, whereas nine accessions EC 667512, EC 667587, EC 667369, EC 667423, EC 667356, EC 667489 and EC 667533 were identified as potential ones by using crossover and non-crossover interactions concept. Of these accessions EC 667369 and EC 667533 have been identified as high yielding accessions having specific adaptability and responsiveness to specific environment both by regression analysis and crossover and non crossover interactions concept. However, none of the accessions out yielded any of the used checks i.e. DL 85, Jyoti and DWR 28 neither by regression nor cross over and non-cross over interaction analysis.

\section{Introduction}

Genotype and environment interaction is the variation arising from the lack of correspondence between genetic and nongenetic effects in multi-environment trials. The different response of genotypes across the testing environments is considered as a hindrance in selecting and recommending of crop varieties and cause yield fluctuations (Kang, 1988). Genotype x environment interaction may offer opportunity for selection and adaptation of genotypes that showed positive interaction with the specific environment that help in the effective utilization of specifically adapted genotype (Ceccarelli and Grando, 2007). Barley is cultivated during Rabi seasons in India. To 
enhance productivity and production of barley it is advocated that breeders should look for the development of stable varieties that should perform consistently over years and locations. The present investigation was carried out over the years during Rabi seasons in the hot- arid climate of Rajasthan to screen the exotic germplasm of barley against the local checks to identify the better replacement of local checks in terms of yield and other phonological parameters using regression analysis (Eberhart and Russell, 1966 and Perkins and Jinks, 1968) and cross and noncrossover interactions concept (Gail and Simon, 1985). Earlier information on this aspect in barley germplasm is not available.

\section{Materials and Methods}

Forty diverse exotic accessions received from abroad also along with best performing local checks i.e. DL 85, Jyoti and DWR 28 were evaluated in a randomized block design with three replications during five Rabi seasons i.e. from year 2012-13 to year 2016-17 at Regional Station of National Bureau of Plant Genetic Resources, Jodhpur. Thus, evaluation was done broadly in five environments. In each environment plots consisted of four rows of $3 \mathrm{~m}$ length with row to row distance of 15 $\mathrm{cm}$. Recommended doses of $\mathrm{P}_{2} \mathrm{O}_{5}$ @ $30 \mathrm{~kg}$ per ha and $\mathrm{N}_{2} @ 60 \mathrm{~kg}$ per ha were also applied at different time of crop growth. Recommended packages and practices were followed to raise good crop. The data were recorded on five randomly taken plants from middle rows of each plot in each environment on seed yield per plant $(\mathrm{g})$, biological yield per plant $(\mathrm{g})$, harvest index (direct values were used for statistical analysis), number of grains per spikelet, number of fertile tillers per plant, plant height $(\mathrm{cm}$.$) , number of grains per spike$ and 1000-seed weight (g) and data were analyzed separately for each environment. Adjusted progeny means were used for the combined analysis and for the traits exhibiting the presence of $\mathrm{g} x$ e interaction. Regression analysis and analysis to detect the presence of crossover and non-crossover interactions were carried out as per Eberhart and Russell (1966), Perkins and Jinks (1968) and Gail and Simon (1985).

\section{Results and Discussion}

Analysis of variance revealed significant differences among accessions for the eight traits in all five seasons. The combined analysis revealed the presence of $\mathrm{g} x \mathrm{e}$ interaction for seed yield per plant $(\mathrm{g})$, biological yield per plant $(\mathrm{g})$, harvest index (direct values were used for statistical analysis), number of grain per spikelet, (average of 10 randomly taken spikelet from each plant), number of fertile tillers per plant, number of grains per spike and 1000-seed weight (g). Regression analysis enables breeders to select desirable accessions with respect to the responsiveness and stability in different environments. In the studied materials the accessions EC 667567, EC 667471, EC 667384, EC 667441, EC 667500, EC 667613, EC 667550, EC 667603, EC 667533, EC 667533 and EC 667369 had above average performance and responsiveness with respect to seed yield per plant using regression analysis (Table 1). Among these high yielding accessions EC 667567, EC 667471, EC 667384, EC 667441, EC 667500, EC 667613, EC 667550 and EC 667603 can be designated as stable ones with average responsiveness. Though the accessions EC 667533 and EC 667369 are above average yielder and also have shown above average responsiveness coupled with instability. Accession EC 667533 and EC 667369 were highest yielder during Rabi 2013 and Rabi 2014 respectively followed by EC 667533 (Rabi, 2012), EC 667567 (Rabi, 2012), EC 667471, EC 667384, EC 667441, EC 667500, EC 667613, EC 667550 (Rabi, 2015) and EC 667603(Rabi, 2013). The 
accession EC 667533 showed above average performance along with instability for Seed yield per plant, biological yield per plant, 1000 -seed weight, number of fertile tillers per plant and plant height $(\mathrm{cm}$.) being the best performance of this accession for these traits again in Rabi 2013 and accession EC 667369 showed above average performance along with instability for seed yield per plant, biological yield per plant, number of seed per spike, number of fertile tillers per plant and plant height $(\mathrm{cm}$.) being the best performance of this accession for these traits again during Rabi 2014.

The regression technique describes the response pattern of individual accession without differentiating the kind of $\mathrm{g} \mathrm{x} e$ interaction involving change in magnitude of response or direction among the accessions (Baker, 1988 and Virk and Mangat (1991). Baker (1988) described a test, which was initially proposed by Gail and Simon (1985) and illustrated its application to test the kind of interaction in crop plants. The concept of crossover and non-crossover interaction is important in decision making relating to crop improvement strategies (Baker, 1988), since the presence of crossover interaction is substantial evidence in favour of breeding for specific adaptation to certain situations. Baker (1988) further suggested that in the absence of crossover interaction there is little substance for argument in the favour of breeding for adaptation to specific environment. The accessions exhibiting crossover interaction against a standard variety can be said to have specific adaptability and can replace that standard variety in the specific environments.

The existence of prior scientific basis to explain crossover interaction is crucial (Peto, 1982). Thus, it is advantageous to define the varietal combinations among which one has to look for qualitative interaction in advance. There will be enormous multiplicity of all possible varietal pairs for detection of crossover interaction if there is no prior basis for comparison. Such a practice will greatly increase the experiment-wise error rate. In the present case the new accessions were therefore, compared with the best check DL 85 for detection of crossover interaction since the aim was to find a suitable alternative to DL 85.

The $\mathrm{H}$ (heterogeneity of response) and $\mathrm{Q}^{+}$and $\mathrm{Q}^{-}$(for the presence of crossover interaction) against the standard variety DL 85 were estimated for all the 40 accessions for the traits exhibiting the presence of $\mathrm{g} x \mathrm{e}$ interaction, i.e. seed yield per plant $(\mathrm{g})$, biological yield per plant (g), harvest index, plant height, number of seeds per spikelet, number of fertile tillers per plant, number of grains per spike and 1000-seed weight (g) and their significance was tested (Baker, 1984). The accession exhibiting either significant $\mathrm{H}$ or $\mathrm{Q}^{+}$and $\mathrm{Q}^{-}$are given in Table 2 . For seed yield per plant $\mathrm{H}$ was significant for the 40 accessions against DL 85.

The presence of crossover interaction was observed for twenty nine accessions namely; EC 667348, EC 667361, EC 667512, EC 667391, EC 667587, EC 667412, EC 667597, EC 667464, EC 667369, EC 667423, EC 667575, EC 667356, EC 667427, EC 667380, EC 667450, EC 667533, EC 667391, EC 667559, EC 667609, EC 667600, EC 667541, EC 667592, EC 667489, EC 667583, EC 667480, EC 667506, EC 667419, EC 667516, EC 667527 (29 accessions) for seed yield per plant against DL 85.

The 38 accessions i.e. EC 667489, EC 667348, EC 667391, EC 667361, EC 667471, EC 667384, EC 667441, EC 667500, EC 667613, EC 667550, EC 667391, EC 667587, EC 667603, EC 667412, EC 667436, EC 667567, EC 667533, EC 667464, EC 667369, EC 667423, EC 667575, EC 667356, EC 
667427, EC 667380, EC 667391, EC 667609, EC 667600, EC 667541, EC 667489, EC 667583, EC 667480, EC 667506, EC 667419, EC 667516, EC 667550, EC 667391, EC 667587 and EC 667527 exhibited the presence of crossover interaction for biological yield per plant and thirty five accessions namely, EC 667436, EC 667533, EC 667567, EC 667597, EC 667464, EC 667423, EC 667348, EC 667361, EC 667512, EC 667471, EC
667384, EC 667441, EC 667500, EC 667613, EC 667550, EC 667391, EC 667587, EC 667603, EC 667412, EC 667369, EC 667575, EC 667356, EC 667427, EC 667380, EC 667391, EC 667559, EC 667609, EC 667600, EC 667541, EC 667592, EC 667489, EC 667506, EC 667419, EC 667516, EC 667527 exhibited the presence of crossover $\mathrm{g} x \mathrm{e}$ interaction for harvest index.

Table.1 Heterogeneity $(\mathrm{H})$ test of response for the comparison of mean seed yield per plant $(\mathrm{g})$ against the standard variety DL 85 along with $\mathrm{Q}^{+}$and $\mathrm{Q}^{-}$values for crossover interaction and adaptability parameters for the accessions

\begin{tabular}{|c|c|c|c|c|c|c|}
\hline \multirow[t]{2}{*}{ Accession } & \multicolumn{3}{|c|}{ Adaptability Parameters } & \multicolumn{3}{|c|}{ Against DL 85} \\
\hline & $\mathrm{u}+\mathrm{d}_{\mathrm{i}}$ & $B_{i} \pm S E$ & $\sigma^{2} d_{i}$ & $\mathrm{H}$ & $\mathrm{Q}^{+}$ & $Q^{-}$ \\
\hline EC 667356 & 13.47 & $-0.17 * \pm 0.09$ & 0.20 & $105.45^{\#}$ & $78.39^{\$}$ & 99.45 \\
\hline EC 667384 & 12.87 & $0.48 * \pm 0.36$ & 0.07 & $95.85^{\#}$ & 84.67 & 58.34 \\
\hline EC 667423 & 13.34 & $0.54 * \pm 0.09$ & 0.10 & $133.56^{\#}$ & 132.56 & $97.67^{\$}$ \\
\hline EC 667441 & 14.32 & $-0.21^{*} \pm 0.18$ & 0.02 & $63.95^{\#}$ & 73.62 & 65.60 \\
\hline EC 667471 & 12.85 & $0.67 * \pm 0.22$ & 0.17 & $152.92^{\#}$ & 69.25 & 77.49 \\
\hline EC 667489 & 13.98 & $-0.12 \pm 0.13$ & 0.10 & $153.41^{\#}$ & 83.48 & $63.69^{\$}$ \\
\hline EC 667500 & 13.17 & $0.23 * \pm 0.04$ & 0.11 & $45.14^{\#}$ & 30.40 & 47.53 \\
\hline EC 667550 & 12.08 & $0.39 * \pm 0.18$ & $0.24 *$ & $112.27^{\#}$ & 76.87 & 63.23 \\
\hline EC 667512 & 14.73 & $-0.75^{*} \pm 0.43$ & 0.03 & $85.98^{\#}$ & 106.72 & $100.77^{\$}$ \\
\hline EC 667533 & 16.55 & $-1.63 * \pm 0.37$ & $0.32 *$ & $55.25^{\#}$ & $93.40^{\$}$ & 154.64 \\
\hline EC 667567 & 14.51 & $-0.90 * \pm 0.70$ & 0.12 & $103.39^{\#}$ & 73.15 & 80.10 \\
\hline EC 667587 & 14.22 & $-0.30 * \pm 0.05$ & 0.16 & $49.45^{\#}$ & 68.65 & $134.65^{\$}$ \\
\hline EC 667369 & 16.19 & $-1.39 * \pm 0.52$ & $0.65 *$ & $101.25^{\#}$ & 55.90 & $45.06^{\$}$ \\
\hline ЕC 667603 & 12.08 & $0.32 * \pm 0.32$ & 0.09 & $67.26^{\#}$ & 41.68 & 72.87 \\
\hline EC 667613 & 13.25 & $-0.01 * \pm 0.05$ & 0.03 & $102.93^{\#}$ & 30.21 & 22.34 \\
\hline Grand Mean & \multicolumn{6}{|c|}{$10.98 \pm 1.01$} \\
\hline & & & & & & \\
\hline
\end{tabular}

- Significant at $\mathrm{P}<0.05$; \# $\mathrm{H}$ was significant against $\mathrm{x}^{2} 0.05$ at $\mathrm{s}-1 \mathrm{df}$, where $\mathrm{s}$ is the number of environments. \$ minimum of either $\mathrm{Q}^{+}$or $\mathrm{Q}^{-}$was significant against "e" value given by Gail and Simon (1985). 
Table.2 Accessions exhibiting significant *, \#H (heterogeneity of response), and $\mathrm{Q}^{+}$and $\mathrm{Q}^{-}$ against standard variety DL 85

\begin{tabular}{|c|c|c|}
\hline Characters & $\mathbf{H}$ & $\mathbf{Q}^{+}$and $\mathbf{Q}^{-}$ \\
\hline $\begin{array}{l}\text { Seed yield per plant } \\
\text { (g) }\end{array}$ & All accessions & 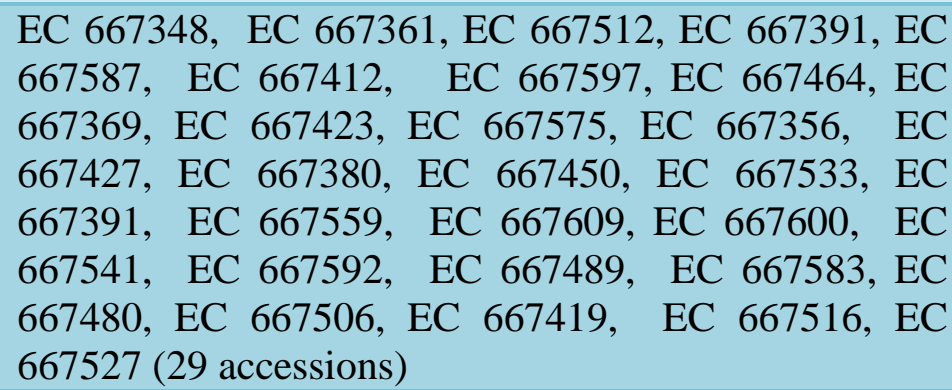 \\
\hline $\begin{array}{l}\text { Biological yield per } \\
\text { plant (g) }\end{array}$ & $\begin{array}{l}\text { All accessions } \\
\text { except and } \\
\text { EC } 667597\end{array}$ & 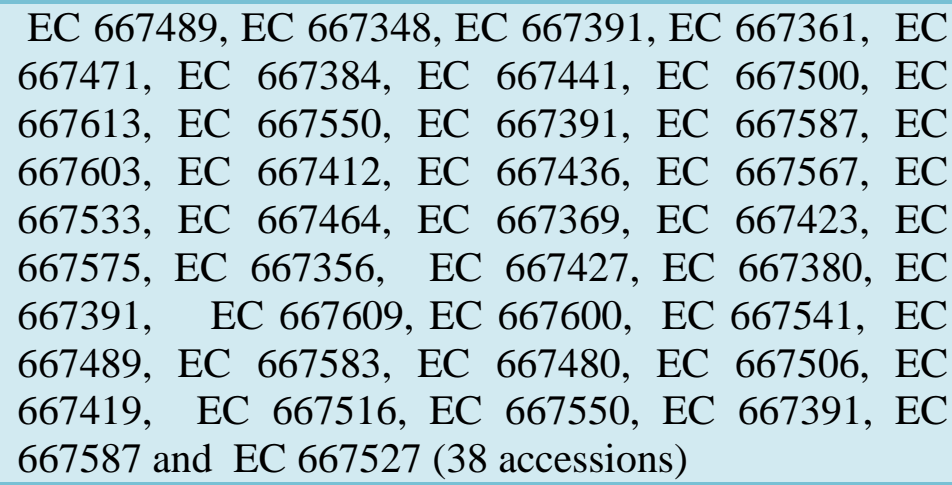 \\
\hline Harvest index & All accessions & $\begin{array}{l}\text { EC 667436, EC } 667533 \text {, EC } 667567 \text {, EC } 667597, \text { EC } \\
667464 \text {, EC } 667423 \text {, EC } 667348 \text {, EC } 667361 \text {, EC } \\
667512 \text {, EC } 667471 \text {, EC } 667384 \text {, EC } 667441 \text {, EC } \\
667500 \text {, EC } 667613 \text {, EC } 667550 \text {, EC } 667391 \text {, EC } \\
667587 \text {, EC } 667603 \text {, EC } 667412 \text {, EC } 667369 \text {, EC } \\
667575 \text {, EC } 667356 \text {, EC } 667427 \text {, EC } 667380 \text {, EC } \\
667391 \text {, EC } 667559 \text {, EC } 667609 \text {, EC } 667600 \text {, EC } \\
667541 \text {, EC } 667592 \text {, EC } 667489 \text {, EC } 667506 \text {, EC } \\
667419 \text {, EC } 667516 \text {, EC } 667527 \text { (35 accessions) }\end{array}$ \\
\hline $\begin{array}{l}\text { Number of seeds per } \\
\text { spike }\end{array}$ & $\begin{array}{l}\text { All } \\
\text { accessions }\end{array}$ & 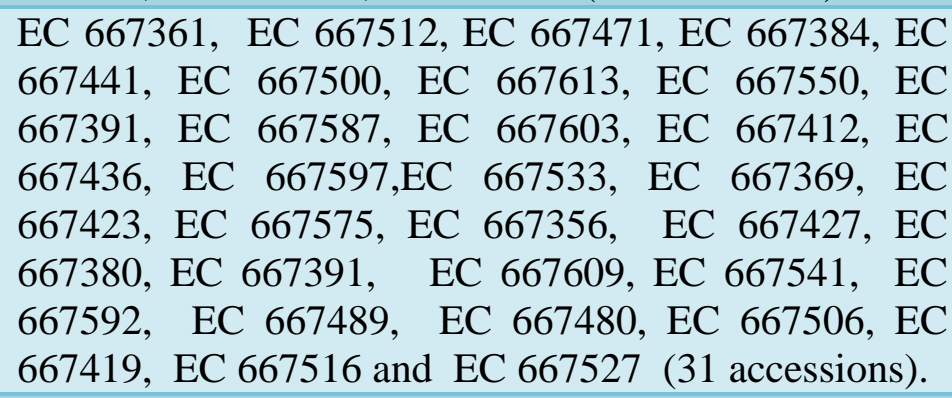 \\
\hline $\begin{array}{l}\text { No. of fertile tillers } \\
\text { per plant }\end{array}$ & $\begin{array}{l}\text { All } \\
\text { accessions } \\
\text { except EC } \\
667427 \text { and } \\
\text { EC } 667506\end{array}$ & $\begin{array}{l}\text { EC 667361, EC 667512, EC 667471, EC } 667384 \text {, EC } \\
667441 \text {, EC } 667500 \text {, EC } 667613 \text {, EC } 667550 \text {, EC } \\
667391 \text {, EC } 667587 \text {, EC } 667533 \text {, EC } 667369 \text {, EC } \\
667412 \text {, EC } 667567 \text {, EC } 667464 \text {, EC } 667423 \text {, EC } \\
667575 \text {, EC } 667356 \text {, EC } 667380 \text {, EC } 667391 \text {, EC } \\
667541 \text {, EC } 667592 \text {, EC } 667489 \text {, EC } 667583 \text {, EC } \\
667480 \text { EC } 667419 \text {, EC } 667516 \text {, EC } 667527\end{array}$ \\
\hline
\end{tabular}




\begin{tabular}{|c|c|c|}
\hline & & accessions) \\
\hline Plant height (cm.) & $\begin{array}{l}\text { All accessions } \\
\text { except EC } \\
667391, \text { EC } \\
667600 \text { and } \\
\text { EC 667583 }\end{array}$ & 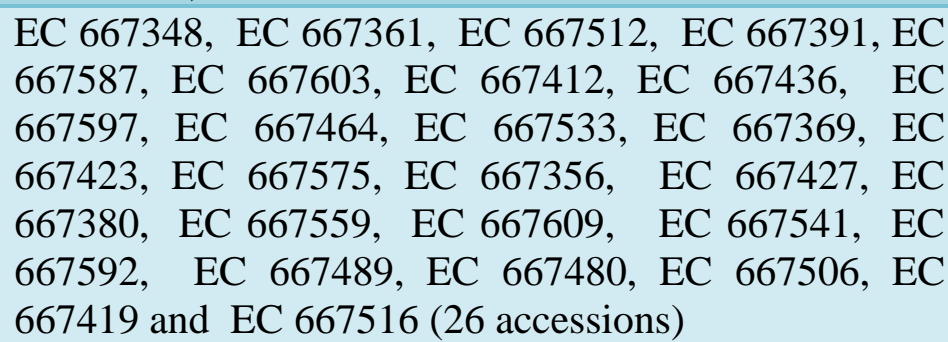 \\
\hline $\begin{array}{l}\text { No. of seeds per } \\
\text { spikelet }\end{array}$ & $\begin{array}{ll}\text { All accessions } \\
\text { except } & \text { EC } \\
667391, & \text { EC } \\
667587, & \text { EC } \\
667603, & \text { EC } \\
667412, & \text { EC } \\
667436, & \text { EC } \\
667533, & \text { EC } \\
667567 & \end{array}$ & 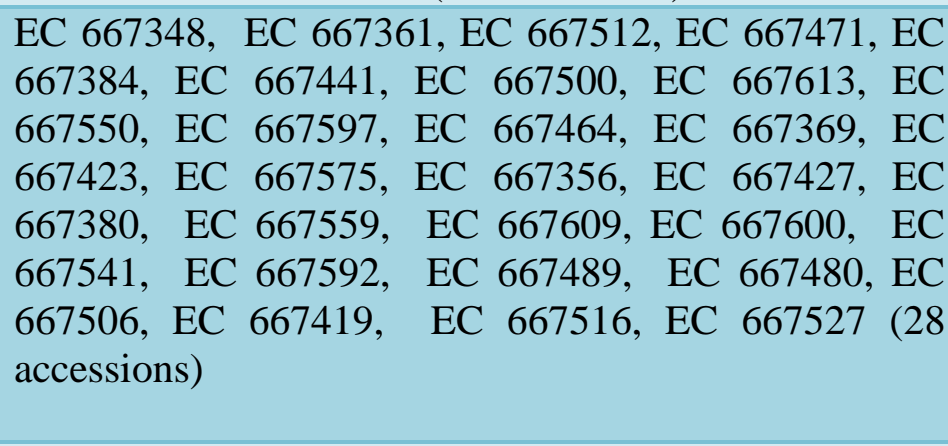 \\
\hline 1000-seed weight (g) & $\begin{array}{l}\text { All accessions } \\
\text { except EC } \\
667464\end{array}$ & 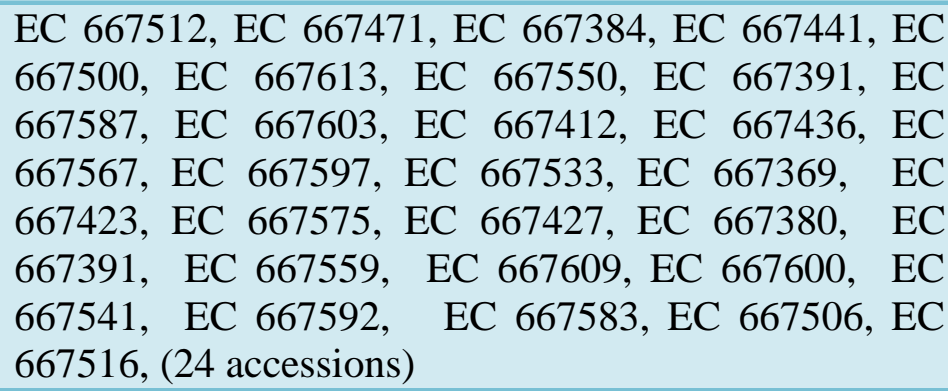 \\
\hline
\end{tabular}

${ }^{*} \mathrm{H}$ was significant against $\mathrm{x}^{2} 0.05$ at s-l df, where $\mathrm{s}$ is the number of environments. \# minimum of either $\mathrm{Q}^{+}$or $\mathrm{Q}^{-}$ was significant against "C" value given by Gail and Simmons (1985).

The 31 accessions exhibited the presence of crossover interaction for number of grains per spike for accessions namely, EC 667361, EC 667512, EC 667471, EC 667384, EC 667441, EC 667500, EC 667613, EC 667550, EC 667391, EC 667587, EC 667603, EC 667412, EC 667436, EC 667597,EC 667533, EC 667369, EC 667423, EC 667575, EC 667356, EC 667427, EC 667380, EC 667391, EC 667609, EC 667541, EC 667592, EC 667489, EC 667480, EC 667506, EC 667419, EC 667516 and EC 667527. The presence of cross over interaction showed by the 28 accessions i.e. EC 667361, EC 667512, EC 667471, EC 667384, EC 667441, EC 667500, EC 667613, EC 667550, EC 667391, EC 667587, EC 667533, EC 667369, EC 667412, EC 667567, EC 667464, EC 667423, EC
667575, EC 667356, EC 667380, EC 667391, EC 667541, EC 667592, EC 667489, EC 667583, EC 667480, EC 667419, EC 667516, EC 667527 for number of fertile tillers per plant. The 26 accessions had the presence of cross over interaction for plant height $(\mathrm{cm}$.) were EC 667348, EC 667361, EC 667512, EC 667391, EC 667587, EC 667603, EC 667412, EC 667436, EC 667597, EC 667464, EC 667533, EC 667369, EC 667423, EC 667575, EC 667356, EC 667427, EC 667380, EC 667559, EC 667609, EC 667541, EC 667592, EC 667489, EC 667480, EC 667506, EC 667419 and EC 667516. The 28 accessions expressed the presence of cross over interaction namely; EC 667348, EC 667361, EC 667512, EC 667471, EC 667384, EC 667441, EC 667500, EC 667613, EC 667550, 
EC 667597, EC 667464, EC 667369, EC 667423, EC 667575, EC 667356, EC 667427, EC 667380, EC 667559, EC 667609, EC 667600, EC 667541, EC 667592, EC 667489, EC 667480, EC 667506, EC 667419, EC 667516, EC 667527 for number of seeds per spikelet. The 24 accessions EC 667512, EC 667471, EC 667384, EC 667441, EC 667500, EC 667613, EC 667550, EC 667391, EC 667587, EC 667603, EC 667412, EC 667436, EC 667567, EC 667597, EC 667423, EC 667575, EC 667427, EC 667380, EC 667391, EC 667559, EC 667609, EC 667600, EC 667541, EC 667592, EC 667583, EC 667506, EC 667516 showed the presence of cross over interaction for test weight. However, most of the accessions expressed the presence of crossover interaction but all accessions failed to exhibit crossover interaction for all traits against DL 85 thus, presence or absence of crossover interaction was accession specific and trait specific (Rathore and Gupta 1995). None of the accessions had better performance than any of the three checks.

The conclusion drawn from regression analysis and crossover and non-crossover interactions concept about identifying accessions having specific adaptability differs considerably. The accessions EC 667567, EC 667471, EC 667384, EC 667441, EC 667500, EC 667613, EC 667550, EC 667603, EC 667533 and EC 667369 identified had above average performance having specific adaptability on the basis of regression analysis failed to exhibit significant $\min \left(\mathrm{Q}^{+}\right.$ or $\mathrm{Q}^{-}$) against standard variety DL 85 . On the other hand the accessions EC 667423, EC 667587, EC 667575, EC 667489, IC103190, EC 667506, EC 667512 EC 667533 and EC 667369 were identified as having above average performance with specific adaptability on the basis of crossover and non-crossover interaction concept, failed to exhibit stable above average performance and responsiveness for seed yield per plant against all three checks.
A mention may be made of the accessions, EC 667533and EC 667369, which have been identified as a high yielding ones having specific adaptability both by using regression analysis and crossover and non-crossover interaction concepts. These accessions gave significantly higher seed yield than the average performance of all accessions. Thus, accession EC 667533and EC 667369 had specific adaptation rather than possessing general adaptation (Sharma, 1995). None of the accessions out yielded any of the checks used in the present investigation.

\section{References}

Virk, D. S. and B. K. Mangat (1991). Detection of crossover accession $\mathrm{x}$ environment interaction in pearlmillet. Euphytica., 52: 193-199.

Per kins, J. M. and J. L. Jinks (1968). Environmental and accessionenvironmental components of variability IV. Non-linear interaction for multiple inbred lines. Heredity., 23: 525-535.

Gail, M. and R. Simon (1985). Testing for quantitative interaction in Schizophyllum commune. analysis and character. Heredity., 27: 361-372.

Kang, M. S. (1998). Using genotype-byenvironment interaction for crop cultivar development. Adv. Agron., 62: 199-252.

Rathore, P. K. and V. P. Gupta (1995). Crossover and non-crossover interactions and regression analysis for seed yield and its components in pea. Crop Improv., 21: 14-18.

Baker, R. J. (1988). Test for crossover accession-environment interaction. Can. J. Plant SeL, 68 (4): 405-410.

R. K. Sharma (1995). Breeding lentil for response to additional nitrogen application. Crop Improv., 22: 139141. 
Peto, R. (1982). Statistical aspects of cancer trials. pp. 867-871. In: E. E. Halnan (ed.), Treatment of cancer. Chapman and Hall, London, U.K.

Eberhart, S. A. and W. A. Russell (1966). Stability parameters for comparing varieties. Crop Sci., 6: 36-40.
Ceccarelli, S. and S. Grando (2007). Decentralized participatory plant breeding. An example of demand driven research. Euphytica, 155: 349360 .

\section{How to cite this article:}

Om Vir Singh, Kartar Singh and Neelam Shekhawat. 2018. Evaluation of Exotic Germplasm of Barley [Hordeum vulgare (L.)] for Stability Parameters. Int.J.Curr.Microbiol.App.Sci. 7(07): 1850-1857. doi: https://doi.org/10.20546/ijcmas.2018.707.220 